\title{
Molecular Detection of blaTEM, blaCTX-M and blaSHV Genes in Extended Spectrum $\beta$-Lactamase (ESBL) Escherichia Coli from Clinical Samples
}

Mahesh Kumar Chaudhary ( $\square$ mahesh_3272@yahoo.com )

Mediciti Hospitals https://orcid.org/0000-0002-9713-961X

Indrani Jadhav

Jaipuria Institute of Management Jaipur

Megha Raj Banjara

Tribhuvan University

\section{Research}

Keywords: E.coli, Extended spectrum $\beta$-lactamase, Multidrug resistant

Posted Date: October 29th, 2021

DOI: https://doi.org/10.21203/rs.3.rs-965153/v1

License: (c) This work is licensed under a Creative Commons Attribution 4.0 International License.

Read Full License 


\section{Abstract}

\section{Background}

Extended spectrum $\beta$-lactamases are the group of beta-lactamase enzymes which confer resistance to the oxyimino-cephalosporins and monobactams. Emergence of ESBL producing genes which possess a serious threat for the treatment of infections both in community and hospitals since it is found to be increasing trends of multidrug resistance. This study was focused to find out the ESBLs producing genes.

\section{Methods}

This was a cross-sectional study conducted over a period of 2 years (September 2018 to April 2020) at microbiology laboratory of Nepal Mediciti Hospital. Clinical samples were processed in microbiology laboratory and culture isolates were indetified and characterized by standard microbiological techniques. following standard procedures.Antibiotic susceptibility testing was performed by modified Kirby-Bauer disc diffusion method as recommended by Clinical and Laboratory Standard Institute. Extended spectrum beta-lactamases were phenotypically confirmed by combined disc method.ESBL producing genes i.e. blaTEM,blaCTX-M and blaSHV were confirmed by PCR.

Results

Of the 1449 total E.coli isolates, 323/1449(22.29\%) isolates were multi -drug resistance.Among total MDR Escherichia coli isolates, 215/323(66.56\%) isolates were ESBL producers. The maximum number of ESBL Escherichia coli was isolated from urine 194(90.23\%), followed by sputum 12(5.58\%), swab $5(2.32 \%)$, pus $2(0.93 \%)$ and blood $2(0.93 \%)$. Antibiotic susceptibility pattern of ESBL E.coli producers showed highest sensitivity towards tigecycline $(100 \%)$ followed by polymyxin $b$, colistin and meropenem.Out of 215 phenotypically confirmed ESBL E.coli,only 186(86.51\%) isolates were found to positive by PCR.The last $29(13.49 \%)$ were negative for any of the resistant genes.Among the ESBL genotypes,most common was blaTEM 118(63.4\%) followed by blaCTX-M 68(36.6\%).

\section{Conclusion}

The emergence of MDR and ESBL producing E.coli isolates with high antibiotic resistant rates to commonly used antibiotics and increased predominance of major gene types blaTEM is a serious concern to the clinicians as well as microbiologist. This study forwarded a real massage to all the clinicians for the emergence of XDR and PDR resistant bacteria and preservation of antibiotics for their proper use in near future, if past experience with MDR and ESBLs is any indicator.

\section{Introduction}

Extended-spectrum beta-lactamases (ESBLs) are the group of beta-lactamase enzymes, which hydrolyze and cause resistance to the oxyimino-cephalosporins (cefotaxime,ceftazidime,ceftriaxone,cefuroxime and cefepime) and monobactams(aztreonam), but not 
the cephamycins (cefoxitin and cefotetan) or carbapenems (imipenem, meropenem, and ertapenem), produced by Escherichea coli and Klebsiella pneumonia. ${ }^{1}$

Emergence of resistant bacteria worldwide as a threat to favorable outcomes of treatment of common infections in community and hospital settings. E.coli is one of the commonest pathogen to exhibit multidrug resistance. Important risk factors for infection with MDR and ESBL Escherichia coli are prolonged antibiotic exposure, overstay in hospital, increased use of third generation cephalosporins, severe illness, increased use of intravenous devices or catheters. ${ }^{2}$

The first ESBL was identified from Germany in 1983, from France in 1985, from United States at end of 1980s, and the beginning of the 1990s. ${ }^{3}$ New TEM and the SHV enzymes are still emerging in Europe, and distinct epidemic clones have been found, for example E. coli and K. pneumoniae isolates with SHV-12 in Italy. ${ }^{4}$ Isolates with the CTX-M-9 group are common in Spain and strains with the CTX-M-3 enzymes have been described chiefly in Eastern Europe, although clones producing the CTX-M group 1 (including the CTX-M-15 type) are the most widespread throughout Europe. ${ }^{5,6,7}$

The rapid increase in extended spectrum beta lactamases with the existence of multidrug resistant organisms is a global problem. The prevalence of ESBL producing organisms is more than $20 \%$ in Asia and South Africa. The detection of major genes such as blaTEM,blaCTX-M and blaSHV in ESBL producing E.coli by molecular methods and their antibiotic resistance pattern can provide valuable information about their epidemiology and help in formulation of rational antimicrobial therapy. ${ }^{8}$

In Developing country like Nepal also due to the increasing incidence of ESBL producing Escherichia coli, the cost associated with the consequences also rises, so considered as an economic burden on the patients both in community and in hospital set up. Therefore, this study was conducted with the objectives of studying the spectrum of MDR and ESBL Escherichia coli producing strains and molecular characterization of these resistant genes. Characterization of ESBL Escherichia coli at molecular level may be beneficial to analyze the root cause of ESBL pattern which may help to make a positive contribution to current understanding and knowledge of the situation caused by ESBL Escherichia coli producing strains and for the development of better treatment strategy and prevention of the disease.

\section{Material And Methods}

\subsection{Sample processing and Identification of Organisms}

A cross sectional study was conducted in Microbiology Laboratory of Nepal Mediciti Hospital, Bhaisepati; Nepal from September 2018 to April 2020. The ethical approval was taken from the Ethical Review Board of Nepal Health Research Council (NHRC), Kathmandu, Nepal. A total of 16542 clinical samples sent to the microbiology laboratory were processed and cultured by standard microbiological techniques. The identification of bacterialisolates were carried out by cultural, morphological characters, Gram stain 
and appropriate biochemical tests (triple sugar iron, indole, citrate, urease and motility) following standard procedures.

\subsection{Antibiotic Susceptibility Tests}

Antibiotic susceptibility testing was performed by modified Kirby-Bauer disc diffusion method as recommended by Clinical and Laboratory Standard Institute.The antibiotics used were amikacin $(30 \mu \mathrm{g})$, gentamycin $(10 \mu \mathrm{g})$, ciprofloxacin $(30 \mu \mathrm{g})$, ceftriaxone $(30 \mu \mathrm{g})$, cefotaxime $(30 \mu \mathrm{g})$, ceftazidime $(30 \mu \mathrm{g})$, nitrofurantoin $(300 \mu \mathrm{g})$, norfloxacin $(10 \mu \mathrm{g})$, nalidixicacid $(30 \mu \mathrm{g})$ ofloxacin $(5 \mu \mathrm{g})$, cotrimoxazole $(25 \mu \mathrm{g})$,cefixime $(5 \mu \mathrm{g})$, cefepime $(30 \mu \mathrm{g})$, tigecycline $(15 \mu \mathrm{g})$, imipenem $(10 \mu \mathrm{g})$, meropenem $(10 \mu \mathrm{g})$, polymyxinb $(300 \mu \mathrm{g})$ and colistin $(10 \mu \mathrm{g})$. Plates were incubated aerobically at $37^{\circ} \mathrm{C}$ for 24 hours. Zone diameter in millimeters was measured and organisms were identified as sensitive, resistant and intermediate as per CLSI 2013 guidelines. Escherichia coli strain ATCC 25922 was used as control strain.

\subsection{Screening of ESBL}

The screening was done by disc diffusion technique using $3^{\text {rd }}$ generation cephalosporins (ceftazidime, cefotaxime and ceftriaxone). Isolates resistant to more than one of these agents were identified as possible ESBL producers. ${ }^{9,10}$

\subsection{Confirmation of ESBL}

For confirmation, combined disc test was performed using Ceftazidime (30 $\mu$ g) alone and ceftazidime with clavulanic acid $(30 \mu \mathrm{g} / 10 \mu \mathrm{g})$ and cefotaxime $(30 \mu \mathrm{g})$ and cefotaxime with clavulanic acid $(30 \mu \mathrm{g} / 10 \mu \mathrm{g})$.A difference in zone of inhibition by $\geq 5 \mathrm{~mm}$ of either of ceftazidime clavulanic acid with ceftazidime alone and cefotaxime clavulanic acid with cefotaxime alone was interpreted as confirmed ESBL. ${ }^{11}$

\subsection{Gene Identification}

From confirmed ESBL E.coli,plasmid DNA was extracted using alkaline hydrolysis method.These plasmid DNA served as a template for PCR amplification using blaTEM,blaCTX-M and blaSHV specific primers(Marcogen,Korea). For PCR amplification, $1.5 \mu$ l plasmid DNA was added to $25 \mu \mathrm{l}$ mixture containing $13 \mu \mathrm{l}$ master mixture (Solis Biodyne,Estonia), $10.5 \mu \mathrm{l}$ nuclease free water and $0.5 \mu \mathrm{l}$ each of reverse and forward primers.PCR was performed in 5 Prime/02 thermal cycler using optimized condition.Bibby Scientific,U.K.using optimized condition.For blaTEM gene identification,initial denaturation at $94^{\circ} \mathrm{C}$ for 5 minutes followed by 30 cycles of each of denaturation ( $95^{\circ} \mathrm{C}$ for 45 seconds), annealing at $\left(50^{\circ} \mathrm{C}\right.$ for 45 seconds), and extension at $\left(72^{\circ} \mathrm{C}\right.$ for 30 seconds), and final extension at $\left(72^{\circ} \mathrm{C}\right.$ for 10 minutes).For blaSHV and blaCTX-M genes, initial denaturation at $94^{\circ} \mathrm{C}$ for 5 minutes followed by 30 cycles of each of denaturation $\left(95^{\circ} \mathrm{C}\right.$ for 45 seconds), annealing at $56^{\circ} \mathrm{C}$ for 45 seconds and $62^{\circ} \mathrm{C}$ for 45 seconds respectively, and extension at $\left(72^{\circ} \mathrm{C}\right.$ for 30 seconds), and final extension at $\left(72^{\circ} \mathrm{C}\right.$ for 10 minutes).The amplified product was subjected to gel electrophoresis ( $2 \%$ gel stained with ethidium 
bromide) at 70v for 45 minutes.DNA ladder (100bp) was used to estimate the molecular weight of amplified products.After electrophoresis,gel doc system was used for photo documentation.

\subsection{Control}

For ESBL test,Escherichai coli (ATCC 25922), Klebsiella pneumoniae (ATCC 700603)were taken as negativecontrol and positive control respectively.Confirmed Escherichia coli strains harbouring blaTEM, blaSHV,blaCTX-M were taken as positive control and nuclease free water as negative control.

\subsection{Statistical Analysis}

Data were entered and percentage calculation were analyzed by using Statistical Package for Social Science (SPSS) version 21.

\section{Results}

1449 Escherichia coli isolates were recovered from various clinical samples. The highest number of Escherichia coli was isolated from urine followed by sputum, swab,pus,blood,fluid,foley's tip,vaginal swab, catheter tip,BAL,biopsy,bile suction tube,CVP tip,ET tube. Of the 1449 total E.coli isolates, $323 / 1449(22.29 \%)$ isolates were multi -drug resistance.Among total MDR Escherichia coli isolates, 215/323(66.56\%) isolates were ESBL producers. The maximum number of ESBL Escherichia coli was isolated from urine $194(90.23 \%)$, followed by sputum $12(5.58 \%)$, swab $5(2.32 \%)$, pus $2(0.93 \%)$ and blood 2 (0.93\%).

\begin{tabular}{|ll|}
\hline Specimen & ESBL E.coli No (\%) \\
\hline Urine & $194(90.23 \%)$ \\
\hline Sputum & $12(5.58 \%)$ \\
\hline Swab & $5(2.32 \%)$ \\
\hline Pus & $2(0.93 \%)$ \\
Blood & $2(0.93 \%)$ \\
Total & $215(100.0)$ \\
\hline
\end{tabular}

Antibiotic susceptibility pattern of ESBL E.coli producers showed highest sensitivity towards tigecycline (100\%) followed by polymyxin b, colistin and meropenem. 


\begin{tabular}{|lll|}
\hline \multirow{2}{*}{ Antibiotics } & \multicolumn{2}{l|}{ Antibiotic susceptibility rate No (\%) ESBL E.coli(215) } \\
\cline { 2 - 3 } & Sensitive & Resistant \\
\hline Amikacin(AK) & $197(91.6)$ & $18(8.4)$ \\
\hline Gentamycin(G) & $180(83.7)$ & $35(16.3)$ \\
\hline Ciprofloxacin(CIP) & $125(58.2)$ & $90(41.8)$ \\
\hline Ceftriaxone(CTR) & - & $215(100)$ \\
\hline Cefotaxime(CTX) & 1 & $214(97.3)$ \\
\hline Ceftazidime(CAZ) & - & $215(100)$ \\
\hline Nitrofurantion(NIT)* & $182(93.8)$ & $12(6.2)$ \\
\hline Norfloxacin(NX)* & $109(56.2)$ & $85(43.8)$ \\
\hline Nalidixic acid(NA)* & $9(4.6)$ & $185(95.4)$ \\
\hline Ofloxacin(OF)* & $91(46.9)$ & $103(53.1)$ \\
\hline Tigecycline(TGC) & $215(100)$ & - \\
\hline Imipenem(IPM) & $148(68.8)$ & $67(31.2)$ \\
\hline Meropenem(MRP) & $194(90.2)$ & $21(9.8)$ \\
\hline Polymyxin B(PB) & $215(100)$ & - \\
\hline Colistin(CL) & $215(100)$ & - \\
\hline
\end{tabular}

Two hundred fifteen ESBL E.coli isolates were confirmed by PCR using blaTEM, blaCTX-M and blaSHV specific primers. Out of 215 phenotypically confirmed ESBL E.coli,only 186(86.51\%) isolates were found to positive by PCR.The last 29(13.49\%) were negative for any of the resistant genes.Among the ESBL genotypes,most common was blaTEM 118(63.4\%) followed by blaCTX-M 68(36.6\%).(Figure 3.Figure 4). The co-existence of blaTEM and blaCTX-M in ESBL producing E.coli was 39(20.96\%). No ESBL E.coli isolates co-harbored blaSHV and blaTEM,blaCTX-M and blaSHV or all three genes at the same time.

\begin{tabular}{|ll|}
\hline ESBL genotypes & ESBL producing E.coli $(\mathrm{n}=186)$ No $(\%)$ \\
\hline blaTEM & $118(63.4 \%)$ \\
\hline blaCTX-M & $68(36.6 \%)$ \\
\hline blaTEM + blaCTX-M & $39(20.96 \%)$ \\
\hline blaSHV & $0(0)$ \\
\hline
\end{tabular}

\section{Discussion}


Despite the discovery of antibiotics, emergence of MDR and ESBLs producing bacteria due to the extensive use of extended spectrum cephalosporins (ESCs) since early 1980's is a significant evolution in antimicrobial resistance. Several other factors including misuse of drugs, inappropriate antibiotic treatment, extensive use of antimicrobials has also contributed to the emergence of drug resistant bacteria. The present study was conducted in the department of microbiology laboratory, Nepal Mediciti Hospital during a period of September 2017 to April 2019 with the aim of understanding the antibiotic profile of MDR and ESBL producing Escherichia coli.

The present study documented that the highest number of E.coli isolates were recovered from urine $(n=1098$ (75.77). With regard to urinary tract infection, E.coli showed great extent of resistance to nalidixic acid, co-trimoxazole and third generation cephalosporins. Similar pattern of resistant in urinary isolates of E.coli was shown in Nepal and India. ${ }^{12,13,14}$ In contrast to our result, Perez et.al reported E.coli isolates were $94 \%$ resistant to ceftriaxone ${ }^{15}$ This may be due to the irrational use of third generation cephalosporins ${ }^{16}$ However; a significant degree of susceptibility was found to nitrofurantoin (96.5\%) followed by amikacin $(80.7 \%)$ and gentamycin (73.9\%).Similar findings have been reported in various studies. ${ }^{12,13,14,17,11,18}$ This may be due to the rational use of these drugs in UTIs cases since it is reserved drug for UTIs.

In this study, analysis of antibiotic susceptibility of E.coli isolated from sputum, blood, swab, pus demonstrated a significant degree of susceptibility towards tigecycline $(100 \%)$ followed by colistin ( $98 \%$ to $100 \%)$, polymyxinb ( $97 \%$ to $100 \%$ ), meropenem ( $91 \%$ to $96 \%$ ) and imipenem ( $79 \%$ to $90 \%)$.Similar results were shown in other studies. ${ }^{14,19}$ It was found to be higher resistant pattern of cephalosporins(22\% to $93 \%$ ), fluoroquinolones(26\% to $85 \%$ ), aminoglycosides( $8 \%$ to $59 \%$ ) as compared to urine isolates. Several studies conducted in Nepal showed similar results. ${ }^{12,19,20}$ In contrast to our study,Bamford et al.noted higher susceptibility pattern towards cephalosporins,fluoroquinolones,aminoglycosides. ${ }^{21}$ The increased level of drug resistance is a major concern worldwide since these are the first line drugs recommended internationally. ${ }^{22,23}$ and are irrational used in public and private sectors. ${ }^{24,25 .}$

The present study noted (323/1449)22.29\% MDR E.coli isolates that were suspected of being ESBL producers were confirmed by combined disc method. Prevalence of ESBL E.coli was (215/323)66.56\% which was alarming high. Several studies reported high prevalence i.e.40-70\% of ESBL E.coli among MDR E.coli. ${ }^{11,26,27,28,29,19}$ Kashyap et.al reported $37 \%$ ESBLE.coli. ${ }^{30}$ But the study conducted by Anil chander et.al in 2013 observed only $13.51 \%$ ESBL prevalence in E.coli which is analogous result to other study. ${ }^{31}$, 32. This is not similar with our study due to the variation in geography, study design and selection of type of antimicrobial agents. Theindiscriminate use of beta-lactam antibiotics leads to the generation of selective pressures which have led to the selection of a variety of mutated forms of beta lactamases. ${ }^{33}$. Antibiotic profile of ESBL producing E.coli were found to be higher sensitivity towardstigecycline(100\%),polymyxin B (100\%), colistin(100\%) followed by amikacin(91.6\%),meropenem(90.2\%)and imipenem(68.8\%).Susceptibility to nitrofurantoin was $93.8 \%$ 
against ESBL producing E.coli isolated form urine. So, it is the drug of choice for treating infection caused by ESBL producing E.coli. The result of similar study conducted in Nepal and India. ${ }^{34,14,8}$. High resistant rates were observed to cephalosporins, nalidixic acid followed by fluoroquinolones. Similar findings were reported by Al-Zarouni et. Al. ${ }^{35}$

In the present study, out of 323 MDR E.coli isolates, ESBL E.coli phenotypes were found to be positive in 215(66.56\%) isolates. Similar findings were reported by Dalela et.al, 2012, Ozcakar et.al, 2011. ${ }^{36,37}$ The frequency of phenotypic ESBL positive E.coli 29 (13.49\%) isolates were lacked blaTEM, blaCTX-M and blaSHV genes. Which could be false positive results by phenotypic methods or can be possible presence of other ESBL encoding genes such as SFO, BES, BEL, TLA, GES, PER and VEB types and structural changes in penicillin-binding proteins that result in resistance to $\beta$-lactam antibiotics. ${ }^{36.38 .39 .40}$

In this study, the overall prevalence of ESBL genes was 186 (86.51\%). Which is similar to other findings reported by Marthie et.al, 2009 in South Africa, Ruben et.al, 2014 in Portugal. ${ }^{39,41}$ PCR analysis revealed the presence of blaTEM,blaCTX-M and blaSHV genes in ESBL producing E.coli was $118(63.4 \%), 68(36.6 \%)$ and $0(0)$ respectively. In the present study,blaTEM was the most predominant genotype of ESBL among E.coli isolates. This study is well supported by Ruben et.al,2014 in Portugal,Noha et.al,2020 in Upper Egypt,Majid et.al,2017 in Iran,Pandit et.al,2020 in Nepal,Bali et.al,2010 in Turkish.Michael et.al,2018 in Iraq,Jena et.al,2017 inIndia, Seyedjavadi et.al,2016. ${ }^{41.42,40,43,44,45,46,47}$

However, several literatures reported the prevalence of balTEM type ESBL producing E.coli was less than this study.In Nepal,some study done by Pokhrel et.al,2014,Lohani et.al,2019 reported 29.2\%,34.6\% blaTEM type ESBL E.coli respectively. ${ }^{48.49}$

In recent years,non-TEM and non-SHV plasmid mediated ESBLs mainly the CTX-M gene, a predominant type of ESBL found in many regions of the world, including Asia,South America,Europe and Africa have been reported and it has been explained under the term "CTX-M $\beta$-lactamase pandemic". ${ }^{50,51,52}$

In the present study, the prevalence of blaCTX-M genes were found to be 68 (36.6\%) which concurs with various reports demonstrating the extensive worldwide dissemination of balCTX-M genes in ESBL producing E.coli isolates. ${ }^{53}$ However, another study from Nepal has reported the high prevalence of blaCTX-M genes (95.2\%) by Pokhrel et.al 2014 and (100\%) by Lohani et.al 2019 and (91.4\%) by Parajuli et.al, 2016. ${ }^{48,49,54}$ Similarly, George et.al, 2015 reported high prevalence of CTX-M type E.coli (91.8\%) in India. ${ }^{55}$ Moreover, the lower prevalence of CTX-M gene among ESBL producing E.coli does not co-relate with study done by Moses et.al. and Sharma et.al. ${ }^{56,57}$ Kiratisin et.al. reported balCTX-M (99.6\%) of ESBL producing E.coli from Thailand. ${ }^{58}$

The differences in frequencies of the prevalence of these genes may be as a result of differences in time by which isolates were collected and differences in volume and type of antibiotic consumption. ${ }^{59}$ 
Furthermore, multiple harboring of genes in a single ESBL producing E.coli was also noted. The most common combination gene was blaTEM + blaCTX-M type 39 (20.96\%). Our finding is in agreement with the study by Lohani et.al where (21.2\%) of balTEM and blaCTX-M genes were reported. ${ }^{49}$ Similar report was shown by Majid et.al.2017. ${ }^{40}$ Whereas genotypic combination of blaSHV + balCTX-M,blaSHV + blaTEM and blaSHV +blaCTX-M +blaTEM were not detected.

The presence of multiple genotypes in a single isolate might be the result of complex antibiotic resistance pattern. ${ }^{60}$ Our findings does not agree with the study of Kaftandzieva et al, 2012 and Ibrahim et.al, 2015 where they reported blaTEM and bla SHV type (16\%) and (2.27\%) respectively. ${ }^{61,62}$ Similarly, El bouamri et.al,2015 reported CTX-M +TEM and CTX-M +SHV type (6\%) and (12\%) respectively. ${ }^{63}$

Regarding the blaSHVgene,no blaSHV type E.coli was detected in our study. Which is similar to the study in China. ${ }^{64}$ However, several findings in Nepal reported the prevalence of blaSHV gene. ${ }^{48,49,54}$ But the prevalence of blaSHV gene reported by Varkey et.al,2014 in India was quite high (66\%). ${ }^{65}$

\section{Conclusion}

In conclusion, the present study highlights the emergence of MDR and ESBL producing E.coli isolates with high antibiotic resistant rates to commonly used antibiotics and increased predominance of major gene types blaTEM is a serious concern to the clinicians as well as microbiologist. Since the spread of MDR and ESBL producing E.coli has been increasing rapidly worldwide including developing country like Nepal, treatment options for resistant bacteria have been increasingly sorted. In the present study, no resistance was documented to tigecycline, polymyxin $b$, and colistin suggesting the suitable drug of choice for treating ESBL producing E.coli causing life threatening infections. Therefore,molecular detection and identification of ESBL producing bacterial isolates should be essential at routine laboratory level. Of particular concern, our findings emphasizes the need for implementation of strict antibiotic policy,clinical care management and antibiotic stewardship program absolutely required in each and every health sectors by all concern authorities. This study forwarded a real massage to all the clinicians for the emergence of XDR and PDR resistant bacteria and preservation of antibiotics for their proper use in near future, if past experience with MDR and ESBLs is any indicator.

\section{Declarations}

\section{CONFLICT OF INTEREST}

The authors declare no conflict of interest.

\section{ACKNOWLEDGEMENT}

We would like to acknowledge Nepal Mediciti Hospital, Nepal for providing ethical approval and research work. We also thank to the microbiology laboratory staffs for their valuable support to complete this 
work.

\section{References}

1. Lal P, Kapil A, Das BK and Sood S. Occurrence of TEM and SHV gene in extended spectrum beta lactamases (ESBLs) producing Klebsiella spp. isolated from a tertiary care hospital. Indian Journal Medica.2007; 125: 173-178.

2. Chaudhary U, Aggarwal R. Extended spectrum $\beta$-lactamases (ESBL): Emerging threat to clinical therapeutics. Indian J Med Microbiol.2004; 22(2):7 https://doi.org/10.1016/S0255-0857(21)02884-X

3. Rice, L.B., Willey, S.H., Papanicolaou, G.A., Medeiros, A.A.,Eliopoulos, G.M., Moellering, R.C.J., Jacoby, G.A.. Outbreak of ceftazidime resistance caused by extended-spectrum betalactamases at a Massachusetts chronic-care facility. Antimicrob.Agents Chemother. 1990; 34 (11), 2193-2199. https://doi.org/10.1128/AAC.34.11.2193

4. Perilli, M., Segatore, B., Mugnaioli, C., Celenza, G., Rossolini, G.M.,Stefani, S., Luzzaro, F., Pini, B., Amicosante, G. Persistence of TEM-52/TEM-92 and SHV-12 Extended-spectrum beta-lactamases in clinical isolates of Enterobacteriaceae in Italy. Microb. Drug Resist.2011; 17 (4), 521-524. DOI: 10.1089/mdr.2011.0059

5. Canton, R., Novais, A., Valverde, A., Machado, E., Peixe, L.,Baquero, F., Coque, T.M. Prevalence and spread of extended-spectrum beta-lactamase producing Enterobacteriaceae in Europe. Clin.

Microbiol. Infect.2008; 1:144-153. DOI: 10.1111/j.1469-0691.2007.01850.x

6. Coque, T.M., Baquero, F., Canton, R. Increasing prevalence of ESBL-producing Enterobacteriaceae in Europe. Euro. Surveill.2008a; 13 (47), 1-11. DOI:10.2807/ese.13.47.19044-en

7.Coque, T.M., Novais, A., Carattoli, A., Poirel, L., Pitout, J., Peixe,L., Baquero, F., Canto' n, R., Nordmann, P. Dissemination of clonally related Escherichia coli strains expressing extendedspectrum beta- lactamase CTX-M-15. Emerg. Infect. Dis.2008b; 14 (2), 195-200.doi: 10.3201/eid1402.070350

8. Kaur, M. and Aggarwal, A. (2013) Occurrence of the CTX-M, SHV and the TEM Genes among the Extended Spectrum Beta-Lactamase Producing Isolates of Enterobacteriaceae in a Tertiary Care Hospital of North India. Journal of Clinical and Diagnostic Research, 7, 642-645.

https://doi.org/10.7860/JCDR/2013/5081.2872

9. Coudron PE,Moland ES,Sanders CC.Occurrence and detection of extended spectrum beta-lactamases in members of the family Enterobacteriaceae at a veterans medical center: seek and you may find.J.Clin Microbial.1997; 35(10):2593-97. https://doi.org/10.1128/JCM.35.10.2593-2597.1997

10. Babypadmini S,Appalaraju B.Extended spectrum beta-lactamases in urinary isolates of Escherichia coli and Klebsiella pneumoniae-Prevalence and susceptibility pattern in a tertiary care hospital.Indian $\mathrm{J}$ 
Med Microbiol.2004; 22(3):172-174 https://doi.org/10.1016/S0255-0857 (21)02830-9

11.Thakur S,Pokhrel N,Sharma M.Prevalence of multidrug resistant enterobacteriaceae and extended spectrum beta-lactamase producing E.coli in urinary tract infection. Research Journal of Pharmaceutical, Biological and Chemical Sciences.2013; 4:1615-1621.

12. Subedi S,Chaudhary M,Shrestha B.High MDR AND ESBL Producing Escherichia coli and Klebsiella pneumoniae from Urine,Pus and Sputum Samples. British Journal of Medicine \& Medical Research.2016; 13(10):1-10.http://dx.doi.org/10.9734/BJMMR/2016/23350

13.Rimal U,Thapa S,Maharjan R.Prevalence of Extended Spectrum Beta-Lactamase Producing Escherichia coli and Klebsiella species from Urinary Specimens of Children attending Friendship International Children's Hospital.Nepal Journal of Biotechnology.2017; 5(1):32-

38.http://dx.doi.org/10.3126/njb.v5i1.18868

14. Kumar D,Singh AK,Ali R,Chander Y.Antimicrobial Susceptibility Profile of Extended Spectrum $\beta$ Lactamase (ESBL) Producing Escherichia coli from Various Clinical Samples. Infect Dis.2014; 7:18.https://doi.org/10.4137/idrt.s13820https://doi.org/10.4137/idrt.s13820

15. Perez F,Endimiani A,Hujer KM,Bonomo RA.The continuing challenge of ESBLs. CurrOpin Pharmacol.2007; 7:459-469. https://doi.org/10.1016/j.coph.2007.08.003

16. Shobha KL,Gowrish RS,Sugandhi R,Sreeja CK.Prevalence of extended spectrum beta lactamases in urinary isolates of Escherichia,Klebsiella and Citrobacter species and their antimicrobial susceptibility pattern in tertiary care hospital.Ind J Pract Doct.2007;3:1-2.

17. Chander A,Shrestha C.Prevalence of extended spectrum beta lactamase producing Escherichai coli and Klebsiella pneumoniae urinary isolates in a tertiary care hospital in Kathmandu, Nepal.BMC Research Notes.2013; 6:487.https://doi.org/10.1186/1756-0500-6-487

18 Chaudhari KB,Singh KG,Parajuli PK,Shrestha K.Incidence and susceptibility of uropathogens isolated among the patients at tertiary care hospital in Eastern Nepal.J Nobel Med Coll.2016;5:51-55. https://doi.org/10.3126/jonmc.v5i2.16318

19.Shrestha B,Shrestha S,Mishra SK,Kattel HP,Tada T,Ohara H, et al.Phenotypic Characterization of Multidrug-resistant Escherichia coli with Special Reference to Extended-spectrum-beta-lactamases and Metallo-beta-lactamases in a Tertiary Care Center.J Nepal Med Assoc.2015;53(198):89-95. https://doi.org/10.31729/jnma.2768

20. Yadav K,Prakash S.Screening of ESBL Producing Multidrug Resistant E.coli from Urinary Tract Infection Suspected Cases in Southern Terai of Nepal.J Infect Dis Diagn.2017;2:2 http://dx.doi.org/10.4172/2576-389X.1000116 
21. Bamford C,Bonorchis K,Ryan A,Hoffmann R,Naicker P,Maloba M, et al.Antimicrobial susceptibility patterns of Escherichia coli strains isolated from urine samples in South Africa from 2007-2011. South Afr J Epidemiol Infect.2012;27(2):46-52. http://dx.doi.org/10.1080/10158782.2012.11441483

22. Gupta $K$,Hooton $T M$,Naber KG,Wullt B,Colgan R,Miller LG,et al.International clinical practice guidelines for the treatment of acute uncomplicated cystitis and pyelonephritis in women: A 2010 update by the Infectious Diseases Society of America and the European Society for Microbiology and Infectious Diseases.Clin Infect Dis.2011;52:e103-e120. https://doi.org/10.1093/cid/ciq257

23. Hooton TM,Scholes D,Gupta K,Stapleton AE,Roberts PL,Stamm WE.Amoxicillin-clavulanate vs ciprofloxacin for the treatment of uncomplicated cystitis in women:a randomized trial.JAMA,2005;293:949- 955.https://doi.org/10.1001/jama.293.8.949

24. Bosch F,vanVuuren C,Joubert G.Antimicrobial resistance patterns in outpatient urinary tract infections: the constant need to revise prescribing habits.S Afr Med J.2011;101(5):328-

331.https://doi.org/10.7196/samj.4346

25. Gumede L,Van der Hoven L,Maseko V,De Kock E,Smuts F,Perovic O,et al.Antimicrobial susceptibility profiles for community-acquired urinary tract pathogens in Gauteng province.Durban:Southern African Journal of Epidemiology and Infection.2011;26(3):122-154.

https://doi.org/10.1080/10158782.2011.11441438

26. Kulkarni DM,Bardapurkar SA,Nilekar SL,More SR.Prevalence of extended spectrum $\beta$-lactamase (ESBL) producing E.coli and Klebsiella species in urinary isolates.IOSR J Dent Med Sci.2016;15:26-29.DOI: $10.9790 / 0853-1506052629$

27. Sharma S,Bhat GK.Virulence factors and drug resistance in Escherichia coli isolated from extraintestinal infection. Ind J Med Microbiol.2007; 25:369-373.https://doi.org/10.4103/02550857.37341

28. Goyal A,Prasad KN,Prasad A,Gupta S,Ghosal U,Ayyagari A.Extended-spectrum $\beta$-lactamases in Escherichia coli and Klebsiella pneumoniae and associated risk factors. Indian J Med Res.2009;129:695700.PMID: 19692752.

29. Rajan S,Prabavathy V.Antibiotic sensitivity and phenotypic detection of ESBL producing E.colistrains causing UTI in a community hospital Chennai,TamilNadu,India. Webmed Central Pharm Sci.2012;3:1-17. http://www.webmedcentral.com/article_view/3840

30. Kashyap G,Gupta S,Mamoria PV,Durlabhji P,Jain D.Increasing prevalence of extended spectrum beta lactamases (ESBLs) producing E.coli and Klebsiella spp in outpatient departments (OPDs) patients in urinary tract infections (UTIs) in tertiary care hospital.Int J Curr Res Rev.2013;5:80-86. 
31. Ibukun A,Tolu O,Brian JM.Extended-spectrum $\beta$-lactamases in isolates of Klebsiella spp and Escherichia coli from Lagos,Nigeria.Nig J Health Biomed Sci.2003;2:53-

60.https://doi.org/10.4314/njhbs.v2i2.11484

32. Shafiq M,Rahman $\mathrm{H}, \mathrm{Q}$ asim M,Ayub N,Hussain S,Khan J,et al.Prevalence of plasmid-mediated ampC $\beta$-lactamases in Escherichia coli and Klebsiella pneumoniae at tertiary care hospital of Islamabad,Pakistan.Euro J Microbiol Immunol.2013;4:267-

271.https://dx.doi.org/10.1556\%2FEuJMI.3.2013.4.5

33. Owens RC Jrl,Rice L.Hospital based strategies for combating resistance.Clinical Infectious Disease.2006;42:S173-81.(Accessed 15 ${ }^{\text {th }}$ April,2006 Available from: https://doi.org/10.1086/500664

34. Khanal S,Joshi DR,Bhatta DR,Devkota U,Pokhrel BM.Beta-lactamase-producing multidrug-resistant bacterial pathogens from tracheal aspirates of intensive care unit patients at National Institute of Neurological and Allied Sciences,Nepal./SRN Microbiology.2013:5.https://doi.org/10.1155/2013/847569

35. Al-Zarouni M,Senok A,Rashid F,Al-Jesmi SM,Panigrahi D.Prevalence and antimicrobial susceptibility pattern of extended-spectrum beta-lactamase producing Enterobacteriaceae in the United Arab Emirates.Med Princ and Prac.2008;17(1):32-36.https://doi.org/10.1159/000109587

36. Dalela G,Gupta S,Jain DK, Mehta P.Antibiotic Resistance Pattern in Uropathogens at a Tertiary Care Hospital at Jhalawar with Special Reference to ESBL,AmpC $\beta$-Lactamase and MRSA Production. $J$ Clin $D$ R: 2012; 6 (4):645-651.

37. Ozcakar ZB,Yalcinkaya F,Kavaz A,Kadioglu G,Elhan AH,Aysev D,Guriz H,Ekim M.Urinary tract infections owing to ESBL-producing bacteria:microorganisms change-clinical pattern does not.Acta Paediatr.2011; 100(8):61-4.https://doi.org/10.1111/j.1651-2227.2011.02262.x

38. Nass T,Poirel $L$ and Nordmann P.Minor extended spectrum $\beta$-lactamases.Clin Microbiol/nfect.2008;14:42-52.https://doi.org/10.1111/j.1469-0691.2007.01861.x

39. Marthie ME,Chrisna V,Eddy PM,Michael GD,Anwar AH,Marleen MK.Detetion of bla SHV,blaTEM and blaCTX-M antibiotic resistance genes in randomly selected bacterial pathogens from the Steve Biko Academic Hospital.Immunol Med Microbiol.2009;56:191-196. https://doi.org/10.1111/j.1574695x.2009.00564.x

40. Majid K,Majid B,Fateh R.Detection of TEM,SHV and CTX-M Antibiotic Resistance Genes in Escherichia coli Isolates from Infected wounds.Medical Laboratory Journal.2017;11(2):3035.http://dx.doi.org/10.18869/acadpub.mlj.11.2.30

41. Ruben F,Paula A,Carla O,Cristina P.Molecular Characterization of ESBL-Producing Enterobacteriaceae in Northern Portugal.The Scientific World Journal.2014;6.https://doi.org/10.1155/2014/782897 
42.Noha AH,Ahmed SK,Eman MF,Adel MH,Medhat AF.Molecular characterization of Extended-spectrum $\beta$ lactamase-producing E.coli recovered from community-acquired urinary tract infections in Upper Egypt.2020; 10:2772 https://doi.org/10.1038/s41598-020-59772-z

43. Pandit R,Awal B,Shrestha SS,Joshi G,Rijal BP,Parajuli NP.Extended-Spectrum $\beta$-lactamase(ESBL) Genotypes among Multidrug-Resistant Uropathogenic Escherichia coli Clinical Isolates from a Teaching Hospital of Nepal.Interdisciplinary Perspectives on Infectious

Diseases.2020;8.http://doi.org/10.1155/2020/6525826

44. Bali EB,Acik L,Sultan N.Phenotypic and molecular characterization of SHV,TEM,CTX-M and extendedspectrum $\beta$-lactamase produced by Escherichia coli,Acinetobacter baumannii and Klebsiella isolates in a Turkish hospital.African Journal of Microbiology Research.2010;4(8):650-

654.https://doi.org/10.5897/AJMR.9000551

45. Michael NS,Saadi AT.Detection of bla CTX-M,blaTEM01 and blaSHV Genes in Multidrug Resistant Uropathogenic E.coli Isolated from Patients with Recurrent Urinary Tract Infections. International Journal of Medical Research \& Health Sciences.2018;7(9):81-89.

46. Jena J,Sahoo RK,Debata NK,Subudhi E.Prevalence of TEM,SHV,and CTX-M genes of extendedspectrum beta-lactamases-producing Escherichia coli strains isolated from urinary tract infections in adults.Biotech.2017;7(4):244.https://doi.org/10.1007/s13205-017-0879-2

47. Seyedjavadi SS,Goudarzi M and Sabzehali F.Relation between blaTEM,blaSHV and blaCTX-M genes and acute urinary tract infections.J Acute Dis.2016;5:71-76.https://doi.org/10.1016/j.joad.2015.07.007

48. Pokhrel RH,Thapa B,Kafle R,Shah PK and Tribuddharat C.Co-existence of $\beta$-lactamases in clinical isolates of Escherichia coli from Kathmandu,Nepal.BMC

Res Notes.2014;7:694.https://doi.org/10.1186/1756-0500-7-694

49. Lohani B,Thapa M,Sharma L,Adhikari H,Sah AK,Khanal AB,Basnet RB and Aryal M.Predominance of CTX-M Type Extended Spectrum $\beta$-lactamase(ESBL) Producers Among Clinical Isolates of Enterobacteriaceae in a Tertiary Care Hospital,Kathmandu,Nepal. The OpenMicrobiology Journal.2019;13:28-33.http://dx.doi.org/10.2174/1874285801913010028

50. Bonnet R. Growing Group of Extended-Spectrum $\beta$-Lactamases:the CTX-M Enzymes.Antimicrob Agents Chemother.2004;48(1)1-14.https://doi.org/10.1128/aac.48.1.1-14.2004

51. Livermore DM,Canton R,Gniadkowski M,Nordmann P,Rossolini GM,Arlet G,Ayala J,Coque TM,KernZdanowicz I,Luzzaro F,Poirel L,Woodford N.CTX-M:changing the face of ESBLs in Europe.J Antimicrob Chemother.2007; 59:165-174.https://doi.org/10.1093/jac/dkl483

52. Canton R and Coque TM. The CTX-M ß-lactamase pandemic.Curr Opin Microbiol.2006; 9:466475.https://doi.org/10.1016/j.mib.2006.08.011 
53. Canton R,Gonzalez-Alba JM and Galan JC.CTX-M enzymes:origin and diffusion.Front.Microbiol.2012;3:110.https://doi.org/10.3389/fmicb.2012.00110

54. Parajuli NP,Maharjan P,Joshi G and Khanal PR.Emerging Perils of Extended Spectrum $\beta$-Lactamase Producing Enterobacteriaceae Clinical Isolates in a Teaching Hospital of Nepal.Biomed Research International.2016; 7. http://dx.doi.org/10.1155/2016/1782835

55. George EA,Sankar S,Jesudasan MV,Sudandiradoss C and Nandagopal B.Molecular characterization of CTX-M type extended spectrum $\beta$-lactamase producing E.coli isolated from humans and the environment.Indian J Med Microbiol.2015;33:73-79.http://dx.doi.org/10.4103/0255-0857.150896

56. Moses A,Bwanga F,Boum Y, and Bazira J. "Prevalence and genotypic characterization of extendedspectrum beta-lactamases produced by gram negative bacilli at a tertiary care hospital in Rural South Western Uganda".British Microbiology Research Journal.2014;4(12):1541-

1550.https://doi.org/10.9734/bmrj/2014/9792

57. Sharma M,Pathak S and Srivastava P."Prevalence and antibiogram of Extended Spectrum $\beta$ lactamase (ESBL) producing Gram negative bacilli and further molecular characterization of ESBL producing Escherichia coli and Klebsiella spp" Journalof Clinical and DiagnosticResearch.2013;7(10):2173-2177.https://doi.org/10.7860/jcdr/2013/6460.3462

58. Kiratisin P,Apisarnthanarak A,Laesripa C,and Saifon P. "Molecular characterization and epidemiology of extended-spectrum- $\beta$-lactamase-producing Escherichia coli and Klebsiella pneumoniae isolates causing Health care-associated infection in Thailand,where the CTX-M family is endemic". Antimicrobial Agents and Chemotherapy.2008;52(8):2818-2824.https://doi.org/10.1128/aac.00171-08

59. Al-Agamy,Mohammad HM,Atef M.Shibl,and Abdelkader F.Tawfik. "Prevalence and molecular characterization of extended-spectrum $\beta$-lactamase-producing Klebsiella pneumoniae in Riyadh,Saudi Arabia." Annals of Saudi Medicine.2009; 29 (4):253.https://doi.org/10.4103/0256-4947.55306

60. Polse RF,Yousif SY,and Assafi MS.Prevalence and molecular characterization of extended spectrum $\beta$ lactamases producing uropathogenic Escherichia coli isolated in Zakho,Iraq.J Microbiol Infect Dis.2016; 6(4):163-167.https://doi.org/10.5799/jmid.328863

61. Kaftandzieva A,Trajkovska-Dokic E,and Panovski N.Prevalence and molecular characterization of extended spectrum $\beta$-lactamases (ESBLs) producing Escherichia coli and Klebsiellapneumoniae.Prilozi.2011;32:129-141.

62. Ibrahim AL-Subol,Youssef N.Prevalence of CTX-M,TEM and SHV Beta-lactamase in Clinical Isolates of Escherichia coli and Klebsiella pneumoniae Isolated from Aleppo University Hospitals,Aleppo,Syria.Arch Clin Infect Dis.2015;10(2):e22540.https://dx.doi.org/10.5812/archcid.22540 
63. El bouamri MC,Arsalane L,Zerouali K,Katfy K,El kamouni Y.Zouhair S.Molecular characterization of extended spectrum $\beta$-lactamase-producing Escherichia coli in a university hospital in Morocco,North Africa.African Journal of Urology.2015;21:161-166.https://doi.org/10.1016/j.afju.2015.02.005

64. Du J,Li P,Liu H,Lu D,Liang H and Dou Y.Phenotypic and molecular characterization of multidrug resistant Klebsiella pneumoniae isolated from a university teaching hospital,China.Plos one.2014; 9(4):e95181.http://doi.org/10.1371/journal.pone.0095181

65. Varkey DR,Balaji V,and Abraham J.Molecular characterization of extended spectrum $\beta$-lactamase producing strains from blood sample.Int J Pharm Sci.2014;6:276-278.

\section{Figure}

Figure is not available with this version. 